\title{
Charcot-Marie-Tooth Disease Type 1B
}

National Cancer Institute

\section{Source}

National Cancer Institute. Charcot-Marie-Tooth Disease Type 1B. NCI Thesaurus. Code C118782.

Charcot-Marie-T ooth disease caused by mutations in the MPZ gene (mapped to chromosome 1q23.3). It results in sensorineural peripheral neuropathy. 